\title{
Basis of Plasma Iron Exchange in the Rabbit
}

\author{
Helmut Huebers, David Uvelli, Antonio Celada, Betty Josephson, and \\ Clement Finch, Departments of Medicine (Hematology Research) and \\ Chemical Engineering, University of Washington, ZD-20 Seattle, \\ Washington 98195
}

A B S T R A C T Rabbit transferrin in vitro is shown to load ferrous iron at random on its specific binding sites. The release of iron to reticulocytes is shown to be an all-or-none phenomenon. The two monoferric transferrins have similar in vivo plasma iron clearance rates and tissue distribution. Diferric transferrin, while giving a similar tissue distribution of radioiron, has a plasma iron clearance rate approximately twice that of the monoferric transferrins at low plasma iron concentrations. This difference diminishes as the plasma iron concentration increases. These results are consistent with a progressively greater in vivo conversion of mono- to diferric transferrin as transferrin saturation increases. The in vivo plasma iron turnover in the rabbit increases progressively as the plasma iron increases, from a mean value of $\sim 0.8 \mathrm{mg} / \mathrm{dl}$ whole blood per $\mathrm{d}$ at a plasma iron concentration of $50 \mu \mathrm{g} / \mathrm{dl}$ to 2.0 at a plasma iron concentration of 300 .

The molecular behavior of transferrin and its iron over this range was investigated using ${ }^{125}$ I-transferrin, $\left[{ }^{55} \mathrm{Fe}\right] \mathrm{monoferric}$ transferrin, and $\left[{ }^{59} \mathrm{Fe}\right.$ e]diferric transferrin. The equilibrium distribution of transferrin between its apo-, mono-, and diferric moieties was similar to that predicted on the basis of the percent saturation and random distribution. Rate constants of iron loading and unloading calculated from the percent saturation and from the clearance rates of $\left[{ }^{55} \mathrm{Fe}\right]-$ monoferric and $\left[{ }^{59} \mathrm{Fe}\right]$ diferric transferrin were similar to those derived from changes in injected ${ }^{125} \mathrm{I}$-apotransferrin. On the basis of these data, it is concluded that the plasma transferrin pool is nonhomogeneous and that the relative size of the mono- and diferric cycles depends on transferrin saturation. A formula is proposed for correcting the plasma iron turnover, thereby eliminating the effect of plasma iron concentration, so as to reflect directly the number of tissue transferrin receptors.

Received for publication 20 April 1982 and in revised form 12 July 1982.

\section{INTRODUCTION}

Although pathways of iron exchange between tissues have been defined (1), the behavior of the plasma iron transport protein itself has been under question (2). Recently, methods have been developed $(3,4)$ that make possible preparation of pure fractions of apo-, mono-, and diferric transferrin. Analytic procedures including both isoelectric focussing and gel electrophoresis permit quantitation of the different species of transferrin as they exist in the plasma. A recent report of such measurements in rabbits presented evidence that transferrin iron did not behave as a homogeneous pool (5). The present study characterizes in more detail the in vitro and in vivo exchange of iron with transferrin and establishes a model in the normal rabbit whereby transferrin iron exchange at any given concentration of plasma iron may be described.

\section{METHODS}

Transferrin was isolated from $275 \mathrm{ml}$ normal rabbit plasma after iron saturation with ferrous ammonium sulfate under spectrophotometric control (3). The separation procedure by means of gel chromatography on Sephacryl S200, ion exchange chromatography on DEAE Sephacel, and conversion of the diferric into the apotransferrin form was the same as described for human transferrin (4). Isolation of apo-, mono-, and diferric transferrin was carried out by isoelectric focussing procedures identical to those described for human transferrin $(3,4)$. In this instance, the starting material was $200 \mathrm{mg}$ of rabbit apotransferrin one-third saturated with ${ }^{55} \mathrm{Fe}$ or ${ }^{59} \mathrm{Fe}$-tagged ferrous ammonium sulfate. Iodination of the diferric transferrin was carried out as described elsewhere (6). The various transferrin preparations were stored in $0.05 \mathrm{M}$ Hepes buffer saline, $\mathrm{pH} 7.4$, at $4^{\circ} \mathrm{C}$. Under these conditions the preparations were stable for at least 2 mo.

Quantitation of the various transferrin fractions and their radioactivity was carried out by urea gel electrophoresis. The method of Makey and Seal (7) with some modification was used. Reagents were prepared with iron-free water and further treated to remove any contaminating iron. The acrylamide, bis-acrylamide, and $10 \mathrm{M}$ urea solutions were each 
mixed for $2 \mathrm{~h}$ with $50 \mathrm{~g} /$ liter of a mixed bed resin (AG 501$\times 8$ Bio-Rad Laboratories, Richmond, CA), filtered and stored at $4^{\circ} \mathrm{C}$. The boric acid buffer, $\mathrm{pH} 8.4$, and the sucrosecontaining diluting buffer were mixed, $25 \mathrm{~g} / \mathrm{liter}$, with a chelating resin (Chelex 100, Bio-Rad Laboratories) for $2 \mathrm{~h}$, then filtered. Other reagents used were checked for iron contamination. In the actual procedure, acrylamide gels containing $6 \mathrm{M}$ urea were prepared in $13 \times 125-\mathrm{mm}$ standard bore electrophoresis tubes (i.d. $10.6 \mathrm{~mm}$ ), which had been acid washed, rinsed free of water, and dried. Before pouring the gels, all reagents were brought to room temperature, mixed quickly in an iron-free tube and poured into a $13 \times 125-\mathrm{mm}$ electrophoresis tube and immediately layered with iron-free water to produce a flat surface on the gel. Each tube contained $6 \mathrm{ml}$ of $10 \mathrm{M}$ urea, $2 \mathrm{ml}$ acryl-bis, $1 \mathrm{ml}$ of $10 \times$ buffer $(0.89 \mathrm{M}$ Tris- $0.89 \mathrm{M}$ borate, $\mathrm{pH} 8.4), 0.5$ $\mathrm{ml} 8 \%$ Temed and $0.5 \mathrm{ml} \mathrm{2 \%}$ ammonium persulfate. After polymerization, the electrophoretic cell (model 155, Bio-Rad Laboratories) was assembled and precooled Tris boratebuffer (1:10 dilution) was added. The cell was then attached to a circulating cooling water bath set at $10^{\circ} \mathrm{C}$ and run at $100 \mathrm{~V}$ for $2 \mathrm{~h}$ for equilibration. $0.5 \mathrm{~h}$ before application time, $130 \mu \mathrm{l}$ of the test plasma was mixed with $870 \mu \mathrm{l}$ of the sucrose-containing diluting buffer. The electrophoretic cell was turned off and $200 \mu \mathrm{l}$ of this dilute solution was applied beneath the buffer at the surface of the polyacrylamide column. Electrophoresis was resumed with $100 \mathrm{~V}$ power only for $\sim 30 \mathrm{~min}$ to allow the protein to enter the gel, after which cooling and stirring were resumed and electrophoresis continued for $17 \mathrm{~h}$. The gel was then removed from the glass tube by rimming and was frozen. Each gel was cut into $\mathbf{5 0}$ slices, 2-mm thick. For ${ }^{59} \mathrm{Fe}$ and ${ }^{125} \mathrm{I}$ counting, pieces were placed in consecutive counting tubes and activity was determined in a gamma counter. For samples containing ${ }^{55} \mathrm{Fe}$, activity was extracted with $1 \mathrm{M}$ perchloric acid and the fluid along with scintillation fluid was placed in a tube for counting in a Packard liquid scintillation counter (Packard Instrument Co., Downers Grove, IL).

The uptake of iron from transferrin by reticulocytes during in vitro incubation was studied $(3,4)$. To produce reticulocytosis, a rabbit was bled $60 \mathrm{ml}$ from the ear artery on days 1,3 , and 4 and blood obtained for the study on day 6 . The reticulocyte count of that blood was $29 \%$ and the hematocrit was 22 . The blood was centrifuged in 4-ml aliquots at $700 \mathrm{~g}$, plasma removed, and cells washed once with 20 ml cold Hanks' balanced salt solution (HBSS). Purified transferrin labeled with both radioiodine and radioiron was diluted with HBSS until the plasma iron was $\sim 90 \pm 5 \mu \mathrm{g} / \mathrm{dl}$. The incubation mixture consisted of $2.5 \mathrm{ml}$ of the individual transferrin solution added to the washed packed erythrocytes to give a hematocrit of $\sim 24 \%$. The mixtures were kept on ice for $10 \mathrm{~min}$ at which time an $0.5 \mathrm{ml}$ zero-time sample was taken, centrifuged at $4^{\circ} \mathrm{C}$ and the supernatant and erythrocytes separated for analyses. The remaining tubes were incubated at $37^{\circ} \mathrm{C}$ and sampled at 60 and $120 \mathrm{~min}$. The supernatant of all samples was subjected to electrophoretic analysis. Because inaccurate results are obtained with very diluted protein solutions, $0.1 \mathrm{ml}$ of carrier rabbit plasma was added to each $0.1 \mathrm{ml}$ of supernatant and then $300 \mu \mathrm{l}$ of sucrose-containing buffer was added before application.

New Zealand male rabbits on a Purina (Ralston Purina Co., St. Louis, MO) diet were used for in vivo studies. They weighed between 1.5 and $3.2 \mathrm{~kg}$. Mean hematocrits, plasma iron, and total iron binding capacity measurements for $\mathbf{4 0}$ animals were $40.5 \pm 2.9$ (mean \pm SD), $185 \pm 57 \mu \mathrm{g} / \mathrm{dl}$, and $323 \pm 35 \mu \mathrm{g} / \mathrm{dl}$, respectively. Additional observations were made to determine the stability of the plasma iron concen- tration. In six nonfasting animals, the average plasma iron concentration was $255 \pm 57 \mu \mathrm{g} / \mathrm{dl}$. After $12 \mathrm{~h}$ of fasting, these same animals had a mean value of $157 \pm 53 \mu \mathrm{g} / \mathrm{dl}$ and after $24 \mathrm{~h}$ of fasting the mean concentration was $155 \pm 47 \mu \mathrm{g} / \mathrm{dl}$. In addition, the plasma iron was sampled every $4 \mathrm{~h}$ over a 24-h period in a second group of six animals. Mean changes in plasma iron values beginning at 8:00 a.m. were $185 \pm 55$, $195 \pm 61,189 \pm 60,171 \pm 62,169 \pm 58,168 \pm 45$, and $172 \pm 33$ $\mu \mathrm{g} / \mathrm{dl}$. It was concluded that food ingestion probably had a significant effect on plasma iron level but that there was no obvious diurnal change.

It was desirable in these studies to have widely varying plasma iron concentrations. In some animals the plasma iron was lowered by the intramuscular injection $12 \mathrm{~h}$ before of $0.5 \mathrm{ml}$ of turpentine ( $\mathrm{T} \& \mathrm{R}$ Chemical Inc., Clint, TX) or $0.5 \mu \mathrm{g} / \mathrm{kg}$ of endotoxin (lipopolysaccharide, Salmonella typhi 0901, Difco Laboratories, Detroit, MI). To obtain a high plasma iron, a freshly prepared 4-ml solution of ferrous ammonium sulfate at $\mathrm{pH} 2$ was infused intravenously over a period of $10 \mathrm{~min}$ by pump. The amount of iron injected was calculated to raise the transferrin saturation to $\sim 80 \%$.

Ferrokinetic measurements were carried out in animals fasted overnight (8). In some studies, $1 \mathrm{ml}$ of a solution of ferrous sulfate containing $1-3 \mu \mathrm{Ci}$ radioiron in $0.1 \mu \mathrm{g}$ of iron at $\mathrm{pH} 2$ was injected intravenously over a 5 -min period. In other studies, a similar amount of radioiron bound in vitro to $4 \mathrm{ml}$ plasma or a solution containing purified transferrin fractions labeled with radioiron was injected. Other experimental formats involving simultaneous injection of several labeled compounds are specified under Results. Thereafter, five or six samples, $1 \mathrm{ml}$ each were drawn for radioactive measurements from the central artery of the ear into a heparinized tube placed on ice, which was spun down within the hour. The sampling time was adjusted to extend beyond the anticipated $t^{1 / 2}$ radioiron disappearance. In addition, 1.5 $\mathrm{ml}$ of blood was drawn at $10 \mathrm{~min}$ and repeated at the approximate $1 / 2$ disappearance time and at twice that interval for plasma iron determination. Some animals were sacrificed by exsanguination $4 \mathrm{~d}$ later, at which time blood and tissue samples were taken for radioactive measurements.

Samples containing ${ }^{59} \mathrm{Fe}$ alone were analyzed directly in a gamma counter. Those containing two isotopes were prepared by first adding $0.25 \mathrm{ml}$ plasma to $0.5 \mathrm{ml}$ of $0.1 \mathrm{~N}$ perchloric acid and then were centrifuged. $10 \mathrm{ml}$ of Aquasol (New England Nuclear, Boston, MA) was added to $0.5 \mathrm{ml}$ of the supernatant and samples were counted in a Tricarb scintillation spectrometer (model 2405, Packard Instrument Co.). Appropriate correction was made for cross-counting. Tissues containing ${ }^{55} \mathrm{Fe}$ and ${ }^{59} \mathrm{Fe}$ were wet ashed and prepared for liquid scintillation counting by the method of Eakins and Brown (9).

Plasma iron turnover (PIT) was calculated as previously described (10) according to the formula:

PIT (mg/dl whole blood/d)

$$
=\frac{\text { Plasma iron }(\mu \mathrm{g} / \mathrm{dl})}{\mathrm{t}^{1 / 2}(\mathrm{~min})} \times \frac{100-(\text { Hct } \times 0.9)}{100} .
$$

Plasma iron was performed according to the methods of the Standardization Committee of the International Society of Hematology (11) and iron binding capacity according to Cook (12). Hematocrits were determined by the microtechnique.

The kinetics of uptake and release by transferrin were evaluated using transferrin tagged with ${ }^{125}$ I, monoferric transferrin tagged with ${ }^{59} \mathrm{Fe}$, and diferric transferrin tagged with ${ }^{55} \mathrm{Fe}$. These proteins, with their varying iron concen- 
trations, were injected simultaneously and the blood was sampled to determine the relative amounts of each in the electrophoretic profile as a function of time. On the basis of preliminary observations it was concluded that three halftime clearances of radioiron were sufficient to establish equilibrium. Therefore, six samples were drawn during three half-time clearances of radioiron and an additional sample was taken at $24 \mathrm{~h}$.

Mathematical considerations. If random distribution on open transferrin sites is assumed, it is possible from the percent saturation of transferrin to determine the proportion of apo-, mono-, and diferric transferrin by the following formulae developed in the Appendix:

$$
\begin{aligned}
& \mathrm{TfFe}_{2}=\frac{S^{2}}{100} \quad \mathrm{TfFe}_{1}=\frac{\mathrm{S}(100-\mathrm{S})}{50} \\
& \mathrm{TfFe}_{0}=100-\mathrm{TfFe}_{1}-\mathrm{TfFe}_{2},
\end{aligned}
$$

where $\mathrm{TfFe}_{2}=$ diferric transferrin, $\quad \mathrm{TfFe}_{1}=$ monoferric transferrin, $\mathrm{TfFe}_{0}=$ apotransferrin, and $\mathrm{S}=$ percent transferrin saturation determined by plasma iron divided by total iron binding capacity. To determine the amount of iron as mono- and diferric transferrin, the relative percentages of mono- and diferric transferrin must be corrected for the double load of iron carried by diferric transferrin. This is done as follows:

$$
\% \mathrm{Fe} \text { as } \mathrm{TfFe}_{1}=\mathrm{TfFe}_{1} / \mathrm{TfFe}_{1}+2 \mathrm{TfFe}_{2} \times 100 ;
$$

the percent $\mathrm{Fe}$ in $\mathrm{TfFe}_{2}$ is given by the formula:

$$
\% \mathrm{Fe} \text { as } \mathrm{TfFe}_{2}=2 \mathrm{TfFe} \mathrm{TfFe}_{1}+2 \mathrm{TfFe}_{2} \times 100 .
$$

In the prediction of in vivo transferrin iron interactions, it was assumed that iron entering and leaving circulation participated in four reactions, each with its own reaction constant (Fig. 1). These included:

(1) binding of iron to apotransferrin to form monoferric transferrin

$$
\left(\mathrm{TfFe}_{0} \stackrel{k_{1}}{\rightarrow} \mathrm{TfFe}_{1}\right)
$$

(2) binding of iron to monoferric to form diferric transferrin

$$
\left(\mathrm{TfFe}_{1} \stackrel{k_{2}}{\rightarrow} \mathrm{TfFe}_{2}\right)
$$

(3) monoferric iron released to tissues leaving apotransferrin

$$
\left(\mathrm{TfFe}_{1} \stackrel{k_{\mathrm{s}}}{\rightarrow} \mathrm{TfFe}_{0}\right)
$$

(4) diferric iron released to tissues leaving apotransferrin

$$
\left(\mathrm{TfFe}_{2} \stackrel{k_{4}}{\rightarrow} \mathrm{TfFe}_{0}\right) \text {. }
$$

Given information concerning transferrin saturation and the in vivo radioiron disappearance rates of mono- and diferric transferrin iron fractions, a model can be constructed to predict iron distribution among transferrin binding sites as a function of time. Briefly, the model uses four apparent rate constants $\left(k_{1}\right.$ to $\left.k_{4}\right)$ to describe the iron-transferrin interaction by the reaction kinetic principles. The value of the individual rate constants is determined for a particular rabbit using the double-isotope technique. When the value of the rate constants is known, it is possible to predict the iron distribution among transferrin as a function of time. In addition, the model can be used to calculate the plasma iron turnover for each animal. Details of the mathematics used in these calculations are shown in the Appendix. A linear

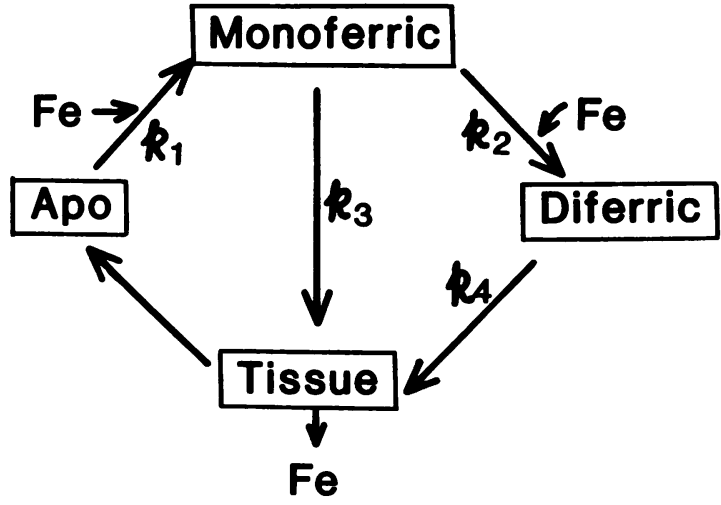

Figure 1 Format of in vivo exchange: Apotransferrin is converted to monoferric transferrin by uptake of one atom of iron from an iron-donating tissue and may be subsequently converted to diferric iron by the addition of a second iron atom. Iron is released to a membrane receptor from either mono- or diferric transferrin, in both instances leaving apotransferrin. The respective reaction constants for these four reactions are designated $k_{1}$ through $k_{4}$.

correlation coefficient was calculated for the predicted vs. observed data. The correlation coefficient will approach 1.0 if the model accurately describes the physical process.

\section{RESULTS}

In vitro studies. Preliminary studies were carried out in which ${ }^{59} \mathrm{FeSO}_{4}$ was added in tracer amounts in vitro to purified rabbit apotransferrin and to sideropenic rabbit plasma, as shown in Fig. 2. The sequential changes in the relative amounts of apo-, mono-, and diferric transferrin with increasing amounts of iron were those predicted from random loading (13).

While the release of iron from monoferric transferrin can only produce apotransferrin, release of iron from diferric transferrin could either result in monoferric or, if both iron atoms were released simultaneously, in apotransferrin. To evaluate this, diferric rabbit transferrin was labeled with ${ }^{125} \mathrm{I}$ and ${ }^{59} \mathrm{Fe}$ and exposed to rabbit reticulocytes. Changes in the proportions of diferric, monoferric, and apotransferrin are summarized in Table I. Only apotransferrin was generated, indicating an all-or-none delivery of iron from the two binding sites of the diferric transferrin in the rabbit system.

In vivo studies. The plasma iron clearance from monoferric transferrin $A$ and monoferric transferrin $B$ was studied in six rabbits with a mean plasma iron of $80 \pm 34 \mu \mathrm{g} / \mathrm{dl}$ and a saturation of $28 \pm 13 \%$. The clearance of monoferric $A$ was $51 \pm 11$ min vs. $48 \pm 11$ for monoferric transferrin $B$ and the ratio between the two clearances was $1.0 \pm 0.1$. The tissue localization of monoferric $A$ in erythrocytes at $5 \mathrm{~d}$ was $84 \pm 27 \%$, in liver $7 \pm 3 \%$, and in spleen $0.6 \pm 0.3 \%$ as compared with 


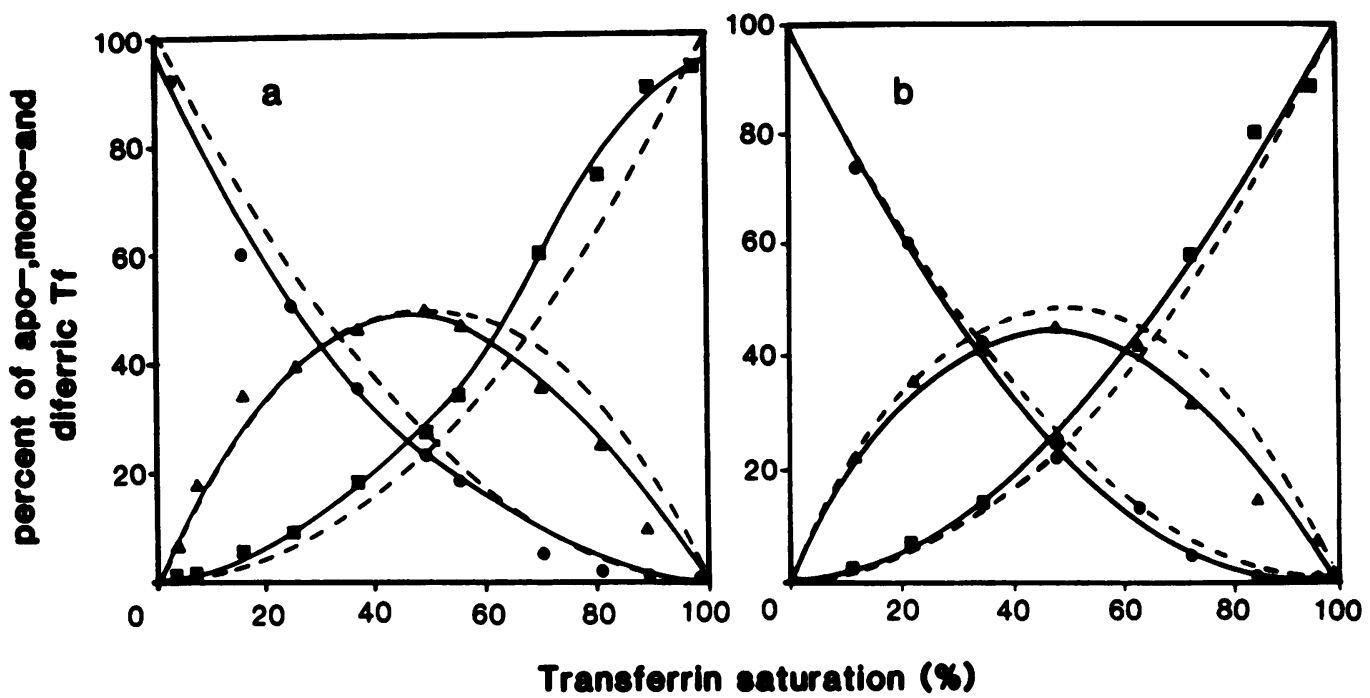

Figure 2 Distribution of iron between the molecular forms of rabbit transferrin. The data were obtained by urea gel electrophoresis of (a) purified ${ }^{125}$ I-labeled apotransferrin $(2.5 \mathrm{mg} /$ $\mathrm{ml}$ in Hanks' balanced salt solution) and (b) raw iron rabbit plasma (SeFe $13 \mu \mathrm{g} / \mathrm{dl}$, unsaturated iron bindings capacity $337 \mu \mathrm{g} / \mathrm{dl})$ to which a tracer amount of ${ }^{125} \mathrm{I}$-a potransferrin $(10 \mu \mathrm{g}$ protein; sp act $20 \mu \mathrm{Ci}^{125} \mathrm{I}, 1 \mathrm{ng}$ protein) has been added. To these solutions increasing amounts of ferrous ammonium sulfate $\left(39.2 \mu \mathrm{g} \mathrm{Fe} \mathrm{F}^{2 \mathrm{f}} / \mathrm{ml}\right.$ in $\left.0.01 \mathrm{~N} \mathrm{HCl}\right)$ were added. Apotransferrin, (๑); monoferric transferrin, $(\boldsymbol{\Delta})$; diferric transferrin, (ם); distribution predicted by the random model, $(---)$.

corresponding distributions of monoferric $B$ of $82 \pm 2.5$, $7 \pm 2$, and $0.6 \pm 0.3 \%$. In addition, a comparison between the tissue distribution of iron injected in the differic form as compared with that of monoferric B transferrin showed similar iron distribution at 1 and $5 \mathrm{~d}$. Respective values for erythrocytes, liver, and spleen at $5 \mathrm{~d}$ were $89 \pm 1.8,8 \pm 3$, and $0.4 \pm 0.1 \%$ as compared with $88 \pm 1.9,6 \pm 2$, and $0.4 \pm 0.2 \%$.

To determine the effect of plasma iron concentration on iron turnover, tandem turnover determinations

TABLE I

Radioiron Uptake from Diferric Transferrin by Rabbit Reticulocytes ${ }^{\circ}$

\begin{tabular}{|c|c|c|c|c|}
\hline $\begin{array}{l}\text { Original iron } \\
\text { concentration }\end{array}$ & Time & ${ }^{30} \mathrm{Fe}$ uptake & $\begin{array}{l}{ }^{50} \mathrm{Fe} \text { lost from } \\
\text { diferric peak }\end{array}$ & $\begin{array}{l}\text { Apotransferrin } \\
\text { formed }\end{array}$ \\
\hline $\begin{array}{c}\text { pg/dl } \\
\text { plasma }\end{array}$ & $\min$ & & $\%$ & \\
\hline \multirow[t]{2}{*}{89} & 60 & 48.5 & 47.0 & 37.9 \\
\hline & 120 & 68.1 & 71.3 & 61.7 \\
\hline \multirow[t]{2}{*}{193} & 60 & 25.4 & 24.5 & 20.6 \\
\hline & 120 & 37.1 & 37.2 & 31.5 \\
\hline
\end{tabular}

- Release of iron from diferric transferrin was followed using electrophoresis to quantitate the disappearance of ${ }^{59} \mathrm{Fe}$ and proteinlabeled ${ }^{125} I$ from the diferric peak and the localization of ${ }^{125} I$ in the apo- and monoferric peaks. were carried out in two groups of animals before and after the intravenous injection of ferrous ammonium sulfate. Care was taken that the distribution of isotope between mono- and diferric transferrin was similar to that present in the animal. Two groups of animals were studied, eight with plasma tagging in vivo and five with plasma tagging in vitro. Base-line turnover values at mean plasma iron concentrations of 137 and 148 $\mu \mathrm{g} / \mathrm{dl}$ were 1.55 and $1.59 \mathrm{mg} / \mathrm{dl}$ whole blood per $\mathrm{d}$. At artificially elevated plasma iron concentrations averaging 248 and 272 , turnover values had increased to 2.0 and $2.1 \mathrm{mg} / \mathrm{dl}$ whole blood per d, respectively. The overall relationship between plasma iron and plasma iron turnover in these two studies and in additional observations on monoferric and diferric relationships is shown in Fig. 3.

The relationship between individual clearance rates of mono- and diferric transferrin at low and high levels of saturation is described in Fig. 4. There were marked differences in clearance rate at low saturations regardless of whether purified plasma fractions or plasma labeling was used, whereas at high transferrin saturations there was little difference.

The in vivo distribution at equilibrium of iron on transferrin binding sites was monitored $24 \mathrm{~h}$ after the injection of ${ }^{125}$ I-tagged apotransferrin (Table II). The predicted distribution based on random loading at the transferrin saturation of each animal was compared 


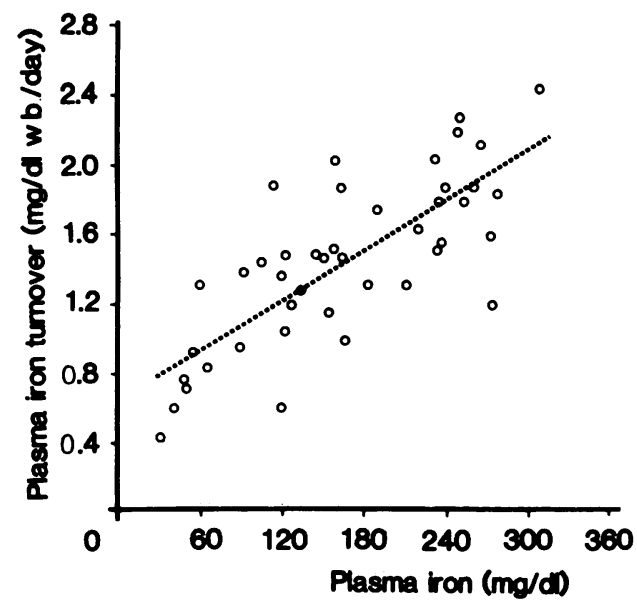

Figure 3 Relationship between plasma iron concentration and plasma iron turnover. These observations were made in three groups of animals and included both in vitro and in vivo radioiron labeling of transferrin. Each point represents a single determination of plasma iron turnover.

with that found by gel electrophoresis. A close agreement was found $(r=0.99 ; P<0.0001)$.

The loading and unloading of iron on the transferrin molecule in vivo was examined in more detail by measuring sequential changes in ${ }^{125} \mathrm{I}$-labeled apotransferrin after its intravenous injection in tracer amounts. A typical study is shown in Fig. 5. The observed changes were then compared with those predicted from our model that used the transferrin saturation and individual clearances of ${ }^{59} \mathrm{Fe}$-labeled monoferric transferrin and ${ }^{55} \mathrm{Fe}$-labeled diferric transferrin. The relation between experimental data based on labeled transferrin and model estimates is shown in Fig. 6.

The derived constants for conversion of apo- to mono- $\left(k_{1}\right)$, from mono- to di- $\left(k_{2}\right)$, from mono- to apo$\left(k_{3}\right)$, and from diferric to apotransferrin $\left(k_{4}\right)$ in 13 animals are shown in Table III. The value of each rate constant and their ratios were strongly dependent on the animal's transferrin saturation (Appendix).

\section{DISCUSSION}

Transferrin is responsible for iron exchange within the body and has been assumed to function kinetically as a single iron pool (14). However, chemical differences between the two iron binding sites have been described, and it has been suggested that site differences in iron loading and unloading might also occur in vivo (2). Because the behavior of transferrin is critical in isotopic measurements of internal iron exchange and particularly in calculations of erythron iron exchange, detailed studies have been carried out by us in several animal species to define transferrin iron behavior.

In the studies reported here, iron added to transferrin has been shown to load randomly on the two iron binding sites. The in vivo distribution of iron between sites has also been shown to be that predicted on the basis of random loading (Table II). Iron uptake must therefore occur one atom at a time; otherwise there would be a disproportionate amount of diferric transferrin present as compared with the proposed random distribution found. This same in vitro and in vivo loading pattern has been observed in other species $(4$, 15). The release of iron from transferrin to reticulo-

\section{Transforrin Saturation ( \%)}

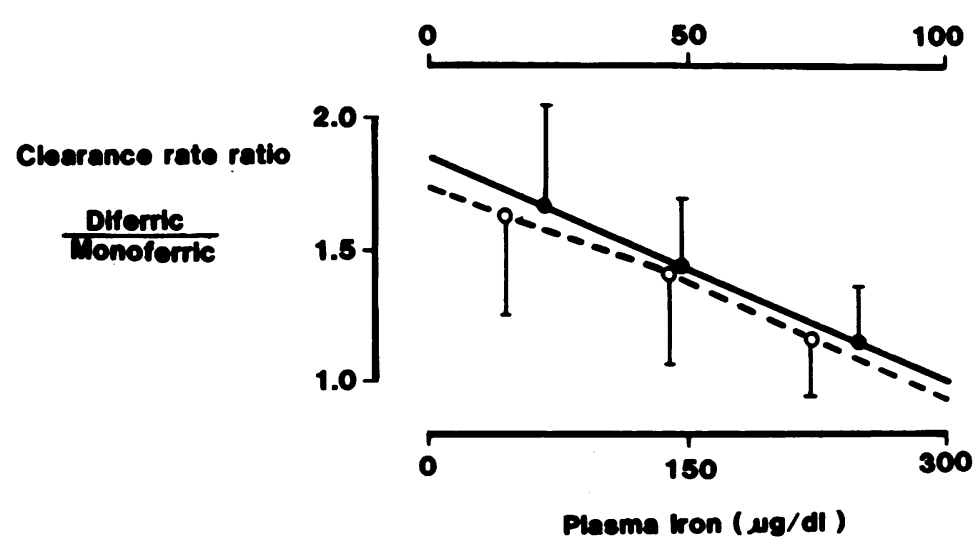

FIGURE 4 Effect of plasma iron and transferrin saturation on clearance rate ratio of diferric to monoferric transferrin. The clearance of diferric transferrin was compared in 12 animals with a preparation of a mixture of monoferric a and $b$ transferrin $(O)$ and in 16 animals with a monoferric $b$ transferric preparation (O). Each point represents the mean of four to six values and the horizontal bars the limits of $1 \mathrm{SD}$. 
TABLE II

Proportions of Apo-, Mono-, and Diferric Transferrin Measured at Equlibrium

Compared to that Predicted from the Transferrin Saturation, Assuming

Random Distribution of Iron on Binding Sites

\begin{tabular}{|c|c|c|c|c|c|c|c|}
\hline \multirow{2}{*}{$\begin{array}{l}\text { Rabbit } \\
\text { code no. }\end{array}$} & \multirow{2}{*}{$\begin{array}{l}\text { Transferrin } \\
\text { saturation }\end{array}$} & \multicolumn{3}{|c|}{ Measured } & \multicolumn{3}{|c|}{ Predicted } \\
\hline & & Tfo & $\mathrm{TfFe}_{1}$ & $\mathrm{TfFe}_{2}$ & Tfo & $\mathrm{TfFe}_{1}$ & $\mathrm{TfFe}_{2}$ \\
\hline
\end{tabular}

$\%$

\begin{tabular}{lrrrrrrr} 
NA1 & 36 & 43 & 40 & 16 & 47 & 40 & 13 \\
BE1 & 45 & 29 & 52 & 19 & 30 & 50 & 20 \\
MAZ & 16 & 73 & 23 & 4 & 71 & 26 & 5 \\
BEZ & 51 & 24 & 50 & 26 & 24 & 50 & 26 \\
MA3 & 20 & 64 & 32 & 4 & 64 & 32 & 4 \\
BE3 & 93 & 2 & 11 & 87 & 0 & 14 & 86 \\
MA4 & 57 & 18 & 48 & 33 & 18 & 50 & 32 \\
BE4 & 81 & 6 & 26 & 68 & 4 & 30 & 66 \\
\hline
\end{tabular}

cytes in vitro has been shown to be an "all-or-none phenomenon." This is also similar to the behavior of transferrin in other species $(3,4,15)$. Furthermore, the distribution of iron to different tissues from the two iron binding sites has been shown to be similar in the rabbit, again in agreement with results in other species (15-17).

The consistency of the in vivo behavior of transferrin in these different species suggests a common model for iron transport. This involves two pathways, the first

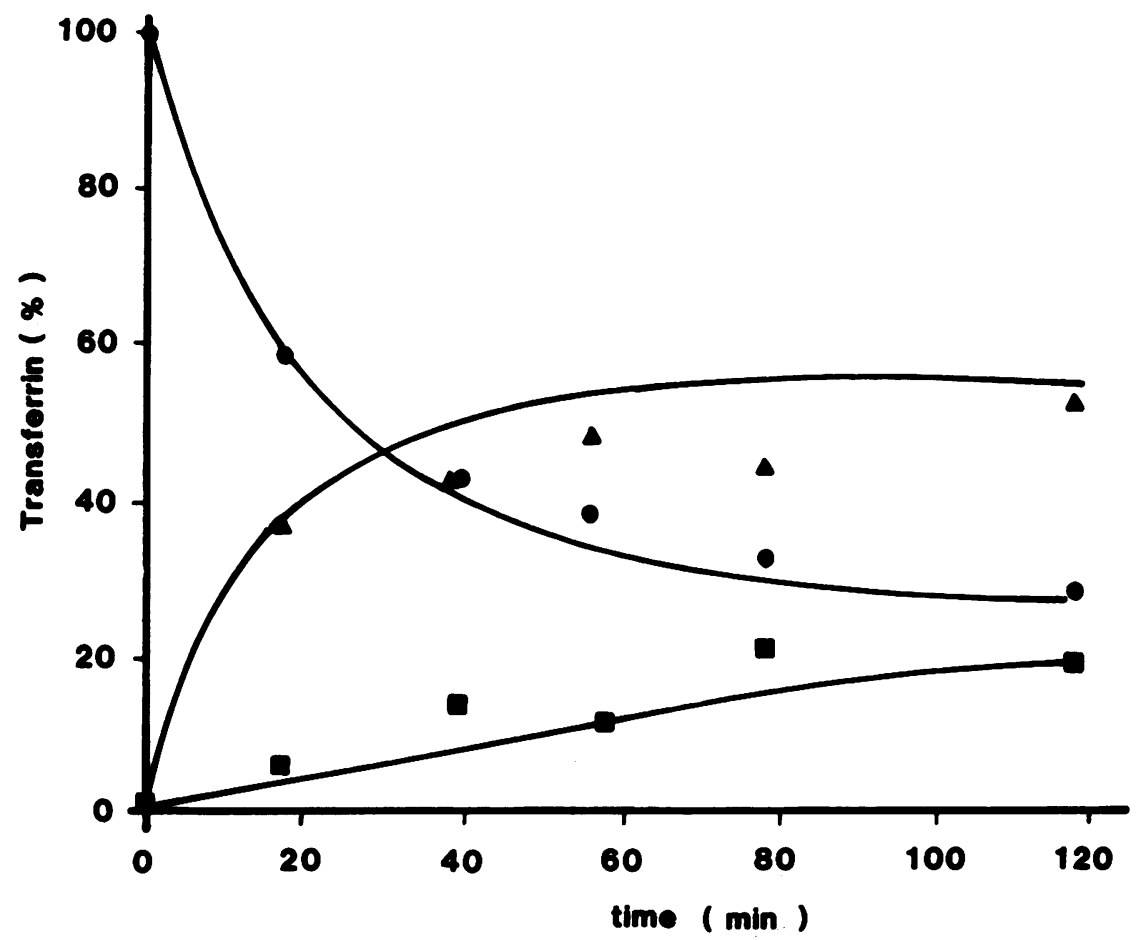

FIGURE 5 Representative example of the loading of injected rabbit ${ }^{125}$ I-apotransferrin with iron in vivo as a function of time. Purified ${ }^{125} \mathrm{I}$-a potransferrin $(15 \mu \mathrm{Ci}$, sp act $20 \mu \mathrm{Ci} / \mathrm{mg}$ protein, was injected in the ear vein of a rabbit. Body wt $1,878 \mathrm{~g}$; serum iron $135 \mu \mathrm{g} / \mathrm{dl}$; iron saturation 48\%). At various intervals heparinized blood samples were taken from the central artery of the ear and centrifuged. Plasma samples were subjected to urea gel electrophoresis and the distribution of iron between the molecular forms of rabbit transferrin was determined (Methods). Apotransferrin, $(\bullet)$; monoferric transferrin, $(\Delta)$; diferric transferrin, $(\square)$. 


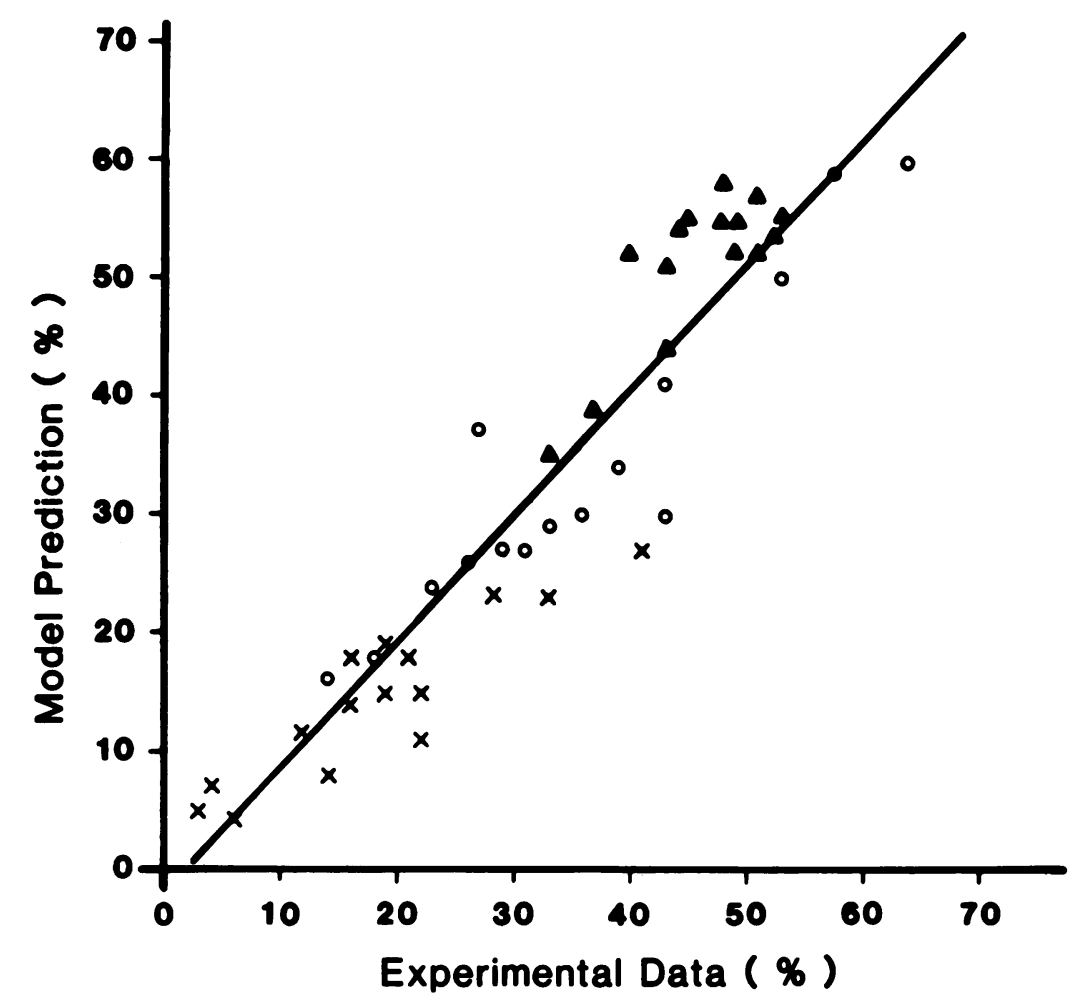

FIGURE 6 A comparison of values derived from the conversion of ${ }^{125}$ I-apotransferrin to other transferrin moieties vs. values predicted from the mathematical model. The model used the percent rabbit transferrin saturation and the $t^{1 / 2}$ for ${ }^{55} \mathrm{Fe}$ and ${ }^{59} \mathrm{Fe}$ to predict the apo- (O), mono$(\Delta)$, and diferric transferrin $(X)$ as a function of time. Quantitation of the distribution of ${ }^{125} I_{-}$ tagged transferrin was achieved by electrophoresis. Results in four animals showed close agreement, $r=0.94$.

represented by the loading and delivery of a single at the receptor site. At low transferrin saturations, molecule of iron and the second a sequential loading where most open sites exist on apotransferrin, the preof two atoms of iron with their simultaneous release dominant pathway is monoferric. At high saturations

TABLE III

Rate Constants Derived from the Disappearance of Radioiron from Mono- and Diferric Transferrin

\begin{tabular}{lccccccr}
\hline $\begin{array}{c}\text { Rabbit } \\
\text { code no. }\end{array}$ & $\mathrm{s}$ & $k_{\mathbf{1}}$ & $k_{\mathbf{2}}$ & $k_{\mathbf{3}}$ & $k_{\mathbf{4}}$ & $k_{\mathbf{1}} / \boldsymbol{k}_{\mathbf{2}}$ & $\boldsymbol{k}_{\mathbf{3}} / \boldsymbol{k}_{\mathbf{4}}$ \\
\hline MA2 & 10 & 0.0067 & 0.0035 & 0.0265 & 0.0622 & 1.9 & 2.3 \\
MA3 & 20 & 0.0073 & 0.0028 & 0.0117 & 0.0224 & 2.6 & 1.9 \\
x4 & 30 & 0.0114 & 0.0044 & 0.0089 & 0.0207 & 2.6 & 2.3 \\
x3 & 35 & 0.0231 & 0.0077 & 0.0134 & 0.0294 & 3.0 & 2.2 \\
MA1 & 45 & 0.0155 & 0.0043 & 0.0050 & 0.0108 & 3.6 & 2.2 \\
BEL & 48 & 0.0231 & 0.0060 & 0.0065 & 0.0130 & 3.9 & 2.0 \\
BE2 & 50 & 0.0284 & 0.0064 & 0.0078 & 0.0127 & 4.4 & 1.6 \\
X1 & 56 & 0.0439 & 0.0089 & 0.0078 & 0.0143 & 4.9 & 1.8 \\
MA4 & 59 & 0.0361 & 0.0068 & 0.0060 & 0.0094 & 5.3 & 1.6 \\
X2 & 64 & 0.0736 & 0.0119 & 0.0089 & 0.0134 & 6.2 & 1.5 \\
BE4 & 78 & 0.1450 & 0.0143 & 0.0070 & 0.0080 & 10.1 & 1.1 \\
BE3 & 93 & $\sim 1.0$ & 0.0339 & 0.0057 & 0.0055 & 9.7 & 1.0 \\
X5 & 99 & $\infty$ & 0.2260 & 0.0050 & 0.0056 & $\infty$ & 1.1 \\
\hline
\end{tabular}


where most of the open sites are on monoferric transferrin, the predominant pathway is diferric. The other consideration is the greater capacity of diferric transferrin to deliver iron to tissues. The proportion of iron delivered by monoferric transferrin and the absolute amounts of iron exchanged by mono- and diferric transferrin at different transferrin saturations are shown in Figs. $7 \mathrm{a}$ and $7 \mathrm{~b}$. At a transferrin saturation of $50 \%$, where precisely half of the iron would be monoferric and half diferric, two-thirds of the iron would be delivered by diferric transferrin. Since half as many diferric transferrin molecules deliver twice as much iron, the efficiency of the diferric moiety is about four times that of its monoferric counterpart.
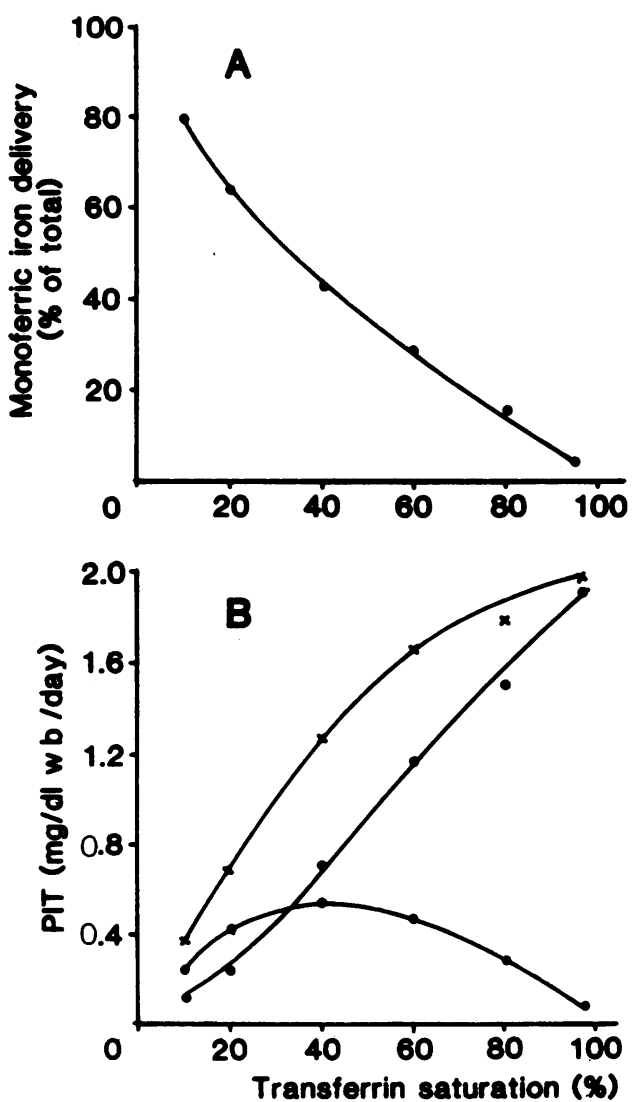

Figure 7 Iron delivery from mono- and diferric transferrin. Data from constants $\left(k_{1}-k_{4}\right)$ derived from studies in experimental animals are used to calculate the relation between plasma iron turnover and the respective proportions contributed by mono- and diferric transferrin. Fig. 7a indicates the decreasing amount of iron delivered to tissues from monoferric iron with increasing transferrin saturation. Fig. $7 \mathrm{~b}$ indicates the absolute amounts of iron delivered by normal animals as a function of transferrin saturation. The three curves in Fig. $7 \mathrm{~b}$ represent total plasma iron turnover $(X)$, diferric iron turnover $(\Delta)$, and monoferric iron turnover (O).
This underlines the dominant role played by diferric transferrin in iron transport and explains the progressive increase in plasma iron turnover observed with increasing plasma iron concentrations and transferrin saturation.

In these studies of normal rabbits, iron supply may be presumed to be more than adequate since the halftime radioiron disappearance indicates a low rate of iron extraction from the plasma (1). Nevertheless, the plasma iron turnover increases with a larger proportion of diferric transferrin. Thus, while tissue requirements, which are the primary determinant of plasma iron turnover, remain unchanged, turnover can change as a function of transferrin saturation. The latter effect is mathematically predictable from the formula:

Converted PIT $=$ Observed PIT

$$
+(\text { plasmatocrit } \times \mathrm{PI}) / 100 \times 0.00475 \text {. }
$$

Using such correction it is possible to define tissue iron requirements independent of plasma iron concentration and to compare one animal's requirements with another. This is particularly relevant to measurements of erythropoiesis. A close correlation has been observed between the number of erythroid precursors (18) or the rate of erythrocytes production (10) and the plasma iron turnover. This relationship should become all the more significant when the effect of plasma iron concentration on iron uptake is removed.

\section{APPENDIX}

\section{Derivation of mathematical models}

Percentages of apo-, mono-, and diferric transferrin in plasma. Let $\mathrm{i}=$ total number of iron molecules in the system; $t=$ total number of transferrin binding sites in the system; $s=$ probability that a transferrin site is filled by iron.

Assuming that any iron molecule has an equal probability of filling any open transferrin binding site and that all iron molecules are rapidly bound to a site,

$$
\mathrm{s}=\mathrm{i} / \mathrm{t} \text {. }
$$

The subject's percent saturation, $S$, equals $100(i / t)$, or

$$
S=100 s
$$

From probability theory, if $s$ is the probability that one transferrin site is filled by iron, then $s^{2}=$ probability that both sites on a transferrin molecule are filled with iron molecules. In this system, $\mathrm{s}^{2}$ also equals the fraction of diferric transferrin molecules. Converting to percent saturation,

$$
\mathrm{TfFe}_{2}=\mathrm{S}^{2} / 100 \text {, }
$$

where $\mathrm{TfFe}_{2}=$ percent diferric transferrin

Since $s$ represents the total probability of a transferrin binding site being filled with iron, and $s^{2}$ represents the probability that both sites on the transferrin molecule are filled with iron, then

$$
\begin{aligned}
s-s^{2}= & \text { probability that only one transferrin site } \\
& \text { is filled with iron. }
\end{aligned}
$$


Since each transferrin molecule has two potential binding sites, the fraction of transferrin molecules with exactly one binding site filled with iron is twice the probability of that event occurring, or

$$
2\left(s-s^{2}\right)=\text { fraction of monoferric transferrin molecules. }
$$

Converting to percent saturation

$$
\mathrm{TfFe}_{1}=\mathrm{S}(100-\mathrm{S}) / 50 \text {, }
$$

where $\mathrm{TfFe}_{1}=$ percent monoferric transferrin. Since the sum of all of the transferrin must equal $100 \%$,

$$
\mathrm{TfFe}_{0}=100-\mathrm{TfFe}_{1}-\mathrm{TfFe}_{2},
$$

where $\mathrm{TfFe}_{0}=$ percent apotransferrin.

Percentage of mono-and diferric iron. Eqs. (7), (6), and (3) allow one to calculate the percentage of transferrin in the apo-, mono-, and diferric states. To calculate the percentage of iron present in monoferric and diferric states, considerations must be given to the fact that $\mathrm{TfFe}_{2}$ has twice the iron as $\mathrm{TfFe}_{1}$. Thus,

$$
\begin{gathered}
\% \mathrm{Fe} \text { as } \mathrm{TfFe}_{1}=\frac{\mathrm{TfFe}_{1}}{\mathrm{TfFe}_{1}+2 \mathrm{TfFe}_{2}} \cdot 100 \\
\% \mathrm{Fe} \text { as } \mathrm{TfFe}_{2}=\frac{2 \mathrm{TfFe}_{2}}{\mathrm{TfFe}_{1}+2 \mathrm{TfFe}_{2}} \cdot 100 .
\end{gathered}
$$

To illustrate the above formulas, suppose the subject's saturation is $40 \%$. Then

$$
\begin{gathered}
\operatorname{TfFe}_{2}=\frac{(40)^{2}}{100}=16 \% \\
\operatorname{TfFe}_{1}=\frac{40(100-40)}{50}=48 \% \\
\mathrm{TfFe}_{0}=100-48-16=36 \% \\
\% \mathrm{Fe} \text { as } \mathrm{TfFe}_{1}=\frac{48}{48+2(16)} 100=60 \% \\
\% \mathrm{Fe} \text { as } \mathrm{TfFe}_{2}=\frac{2(16)}{48+2(16)} 100=40 \%
\end{gathered}
$$

Kinetic model. The random loading model describes the iron distribution at steady state. However, the random model tells nothing of the dynamics of iron binding to transferrin and its subsequent release to tissues. To better understand this kinetic process, a model has been developed that uses reaction kinetic principles to describe the iron-transferrin interactions by a series of rate constants. The kinetic model assumes that iron and transferrin interact in four ways as indicated by the following four equations:

(a) an iron molecule binds to apotransferrin to form monoferric transferrin,

$$
\mathrm{TfFe}_{0}+\mathrm{Fe}-\stackrel{k_{1}}{\rightarrow} \mathrm{TfFe}_{1}
$$

(b) a second iron molecule binds to monoferric transferrin to form diferric transferrin,

$$
\mathrm{TfFe}_{1}+\mathrm{Fe} \stackrel{k_{2}}{\rightarrow} \mathrm{TfFe}_{2}
$$

(c) iron is delivered to the tissues by monoferric transferrin,

$$
\mathrm{TfFe}_{1} \stackrel{k_{3}}{\rightarrow} \mathrm{TfFe}_{0}+\mathrm{Fe} \text {-tissues }
$$

(d) iron is delivered to the tissues by diferric transferrin,

$$
\mathrm{TfFe}_{2} \stackrel{k_{4}}{\rightarrow} \mathrm{TfFe}_{0}+2 \mathrm{Fe} \text {-tissues, }
$$

where Tf, transferrin; $\mathrm{Fe}$, free iron; and $k_{\mathrm{x}}$, reaction rate constant.

The model assumes a constant $\mathrm{Fe}$ concentration, meaning that the iron saturation cannot change significantly during the course of an experiment. Both $k_{1}$ and $k_{2}$ are "apparent" rate constants since the conversion of apo- to mono- and mono- to diferric transferrin involves reaction with a free ion. Thus, $k_{1}=k_{1}^{\prime} \mathrm{Fe}$ and $k_{2}=k_{2}^{\prime} \mathrm{Fe}_{1}$ where $\mathrm{Fe}$ is the free iron concentration and $k_{1}^{\prime}$ and $k_{2}^{\prime}$ are the true rate constants. Since the model requires a constant free iron concentration, we have chosen to use the apparent rate constants for simplicity. The differential equations describing the interactions of (10)-(13) are:

$$
\begin{aligned}
& \frac{\mathrm{d}\left(\mathrm{TfFe}_{0}\right)}{\mathrm{dt}}=-k_{1} \mathrm{TfFe}_{0}+k_{3} \mathrm{TfFe}_{1}+k_{4} \mathrm{TfFe}_{2} \\
& \frac{\mathrm{d}\left(\mathrm{TfFe} \mathrm{e}_{1}\right)}{\mathrm{dt}}=k_{1} \mathrm{TfFe}_{0}-\left(k_{3}+k_{2}\right) \mathrm{TfFe}_{1} \\
& \frac{\mathrm{d}\left(\mathrm{TfFe} e_{2}\right)}{\mathrm{dt}}=k_{2} \mathrm{TfFe}_{1}-k_{4} \mathrm{TfFe}_{2} .
\end{aligned}
$$

Eqs. (14)-(16) form the basis of the kinetic model. If the rate constants $k_{1}, k_{2}, k_{3}$, and $k_{4}$ are known, then the equations can be solved numerically to give the concentration of apo-, mono-, and diferric transferrin at any time $t$. This fulfills the purpose of the model: to predict the iron distribution as a function of time.

To calculate the values of the individual rate constants, consider first the steady-state or equilibrium condition of the system. Since Eqs. (14)-(16) must be valid at all times, it follows that the relationship represented in these equations is true at equilibrium when

$$
\frac{\mathrm{d}\left(\mathrm{TfFe}_{0}\right)}{\mathrm{dt}}=\frac{\mathrm{d}\left(\mathrm{TfFe}_{1}\right)}{\mathrm{dt}}=\frac{\mathrm{d}\left(\mathrm{TfFe}_{2}\right)}{\mathrm{dt}}=0 .
$$

In other words, equilibrium means that as $\mathrm{TfFe}_{1}$ is removed from the system either by conversion to $\mathrm{TfFe}_{2}$ or by removal to the tissue, then a new $\mathrm{TfFe}_{1}$ is created from $\mathrm{TfFe}_{0}$ to replace it. By examining the steady-state condition, two relationships between the rate constants become apparent.

From Eq. (16): $\quad k_{2}=k_{4} \cdot \mathrm{TfFe}_{2} / \mathrm{TfFe}_{1}$

From Eq. (15): $\quad k_{1}=\left(k_{3}+k_{2}\right) \mathrm{TfFe}_{1} / \mathrm{TfFe}_{0}$.

To find the values of $k_{3}$ and $k_{4}$ for a particular subject, we require some experimental data, in particular, the decay rates of two types of tagged iron from the subject. One of the irons, say ${ }^{55} \mathrm{Fe}$, must be injected as nearly pure diferric. The other tag, say ${ }^{59} \mathrm{Fe}$, can have any mono/di distribution, so long as that distribution is known. In following the decay of tagged iron, Eq. (14) describing apotransferrin has no relevance since it contains no tag. Thus, when using tagged iron, Eqs. (14)-(16) can be simplified to:

$$
\begin{aligned}
& \frac{\mathrm{d}\left(\mathrm{Tf}^{\circ} \mathrm{Fe} \mathrm{e}_{1}\right)}{\mathrm{dt}}=-\left(k_{3}+k_{2}\right) \mathrm{Tf}^{\circ} \mathrm{Fe}_{1} \\
& \frac{\mathrm{d}\left(\mathrm{Tf}^{\circ} \mathrm{Fe}_{2}\right)}{\mathrm{dt}}=k_{2} \mathrm{Tf}^{\circ} \mathrm{Fe}_{1}-k_{4} \mathrm{Tf}^{\circ} \mathrm{Fe}_{2},
\end{aligned}
$$

where the asterisk indicates radioactively tagged iron. For pure diferric transferrin (tagged with ${ }^{55} \mathrm{Fe}$ in this example) $\mathrm{Tf}^{55} \mathrm{Fe}_{1}=0$, and Eq. (21) becomes

$$
\frac{\mathrm{d}\left(\mathrm{Tf}^{55} \mathrm{Fe}_{2}\right)}{\mathrm{dt}}=-k\left(\mathrm{Tf}^{55} \mathrm{Fe}_{2}\right) \text {. }
$$



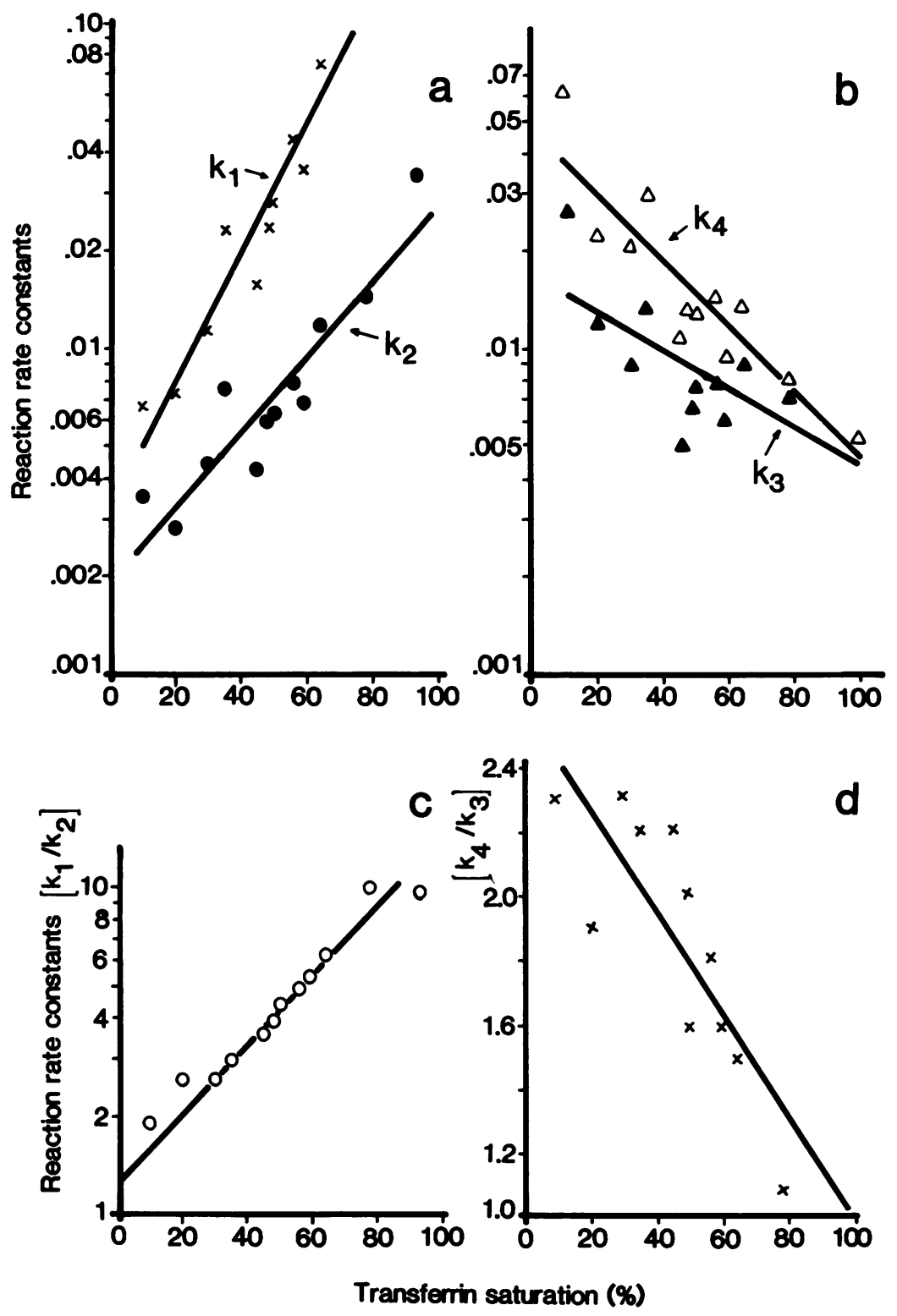

Figure 8 Relationship between the reaction rate constants and transferrin saturation. The constants related to the uptake of iron by monoferric $\left(k_{1}\right)$ or diferric $\left(k_{2}\right)$ transferrin show a positive correlation ( $r=0.96$ and $r=0.92$, respectively) (a) as well as their ratio $(r=0.98)$ (c). The constants related to the iron release by mono- $\left(k_{3}\right)$ or diferric $\left(k_{4}\right)$ transferrin show a negative correlation $(r=-0.69$ and $r=-0.92$, respectively (b). The ratio between these last show a similar negative correlation $(r=-0.88)(d)$.

This equation can be directly solved in terms of the decay half-time of ${ }^{55} \mathrm{Fe}$ :

$$
k_{4}=\frac{\ln (2)}{{ }^{5 t_{1 / 2}}} \text {. }
$$

Thus, the decay half-time of the diferric tag gives the value of $k_{4}$ directly.
The value of $k_{2}$ is found from Eq. (18). Since the percent saturation of the subject is measured, $\mathrm{TfFe}_{1}$ and $\mathrm{TfFe} \mathrm{e}_{2}$ are calculated from Eqs. (6) and (3). Using the $k_{4}$ value from Eq. (23) gives $k_{2}$ directly.

The most difficult rate constant to determine is $k_{3}$. Eqs. (20) and (21) can be solved for $\mathrm{Tf}^{\circ} \mathrm{Fe}_{1}$ and $\mathrm{Tf}^{\circ} \mathrm{Fe}_{2}$ as a function of time by assuming a value for $k_{3}\left(k_{2}\right.$ and $k_{4}$ have 
been determined already). The simultaneous differential equations can be solved by a variety of numerical methods such as the Newton or Runga-Kutta technique. Experimentally, the decay of ${ }^{59} \mathrm{Fe}$ is the sum of $\mathrm{Tf}^{59} \mathrm{Fe}_{1}+\mathrm{TF}^{59} \mathrm{Fe}_{2}$. A series of $k_{3}$ values are used and $\left(\mathrm{Tf}^{59} \mathrm{Fe}_{1}+\mathrm{Tf}^{59} \mathrm{Fe}_{2}\right)$ is found from the solution of Eqs. (20) and (21). The $k_{3}$ value that gives the best fit to the experimental data is determined. For the rabbit data, a modified Newton procedure was used to find the $k_{3}$ that gave the closest estimation of the $t^{1 / 2}$ for ${ }^{59} \mathrm{Fe}$. This is a relatively simple procedure on a programmable calculator. The value of $k_{1}$, the remaining fourth rate constant, was calculated from Eq. (19). Values of the constants calculated as a function of transferrin saturation in the individual experiments are shown in Fig. 8.

Once the rate constants have been determined for a particular subject, the value of $\mathrm{TfFe}_{0}, \mathrm{TfFe}_{1}$, and $\mathrm{TfFe} \mathrm{F}_{2}$ at any time can be calculated from Eqs. (14)-(16) using a numerical method such as the modified Newton procedure. The accuracy of the model in predicting the iron-loading distribution as a function of time has been described in the text.

The plasma iron turnover can also be calculated from the kinetic model. Knowing $k_{2}, k_{3}$, and $k_{4}$, Eqs. (20) and (21) can be used to find the $t^{1 / 2}$ for the saturation of the patient, and the PIT is calculated from this $t \frac{1 / 2}{2}$ value. The advantage of this method is that it finds the $t \frac{1}{2}$ for the subject's percent saturation, which can differ significantly from the $t^{1 / 2}$ of the tagged iron. As discussed in the text, the $t^{1 / 2}$ is a function of the saturation of the tagged iron. Unless the tagged iron has a saturation identical to the subject's saturation, the measured $t^{1 / 2}$ will be in error. Use of the kinetic model, though a more complex procedure, will give a more accurate determination of the PIT.

\section{ACKNOWLEDGMENTS}

This research was supported, in part, by grant HL 06242 from the National Heart, Lung, and Blood Institute, National Institutes of Health. Computational assistance was provided by CLINFO computer system funded under General Clinical Research Center grant RR-37.

\section{REFERENCES}

1. Bothwell, T. H., R. W. Charlton, J. D. Cook, and C. A. Finch. 1979. Iron Metabolism in Man. Blackwell Scientific Publications, Oxford.

2. Aisen, P., and E. B. Brown. 1977. The iron-binding function of transferrin in iron metabolism. Semin. Hematol. 14: 31-53.

3. Huebers, H., E. Csiba, B. Josephson, E. Huebers, and C. A. Finch. 1981. Interaction of human diferric trans- ferrin with reticulocytes. Proc. Natl. Acad.Sci. USA. 78: 621-625.

4. Huebers, H., B. Josephson, E. Huebers, E. Csiba, and C. A. Finch. 1981. Uptake and release of iron from human transferrin. Proc. Natl. Acad. Sci. USA. 78: 25722576.

5. Groen, R., P. Hendricksen, S. P. Young, A. Leibman, and $P$. Aisen. 1982. Molecular ferrokinetics in the rabbit. Br. J. Haematol. 50: 43-53.

6. McFarlane, A. S. 1958. Efficient trace labelling of proteins with iodine. Nature (Lond.). 182: 53.

7. Makey, D. G., and U. S. Seal. 1976. The detection of four molecular forms of human transferrin during the iron binding process. Biochim. Biophys. Acta. 453: 250255.

8. Bauer, W., S. Stray, H. Huebers, and C. Finch. 1981. The relationship between plasma iron and plasma iron turnover in the rat. Blood. 52: 239-242.

9. Eakins, J. D., and E. A. Brown. 1966. An improved method for the simultaneous determination of iron 55 and iron 59 in blood by liquid scintillation counting. Int . J. Appl. Radiat. Isot. 17: 391 .

10. Finch, C. A., K. Deubelbeiss, J. D. Cook, J. W. Eschbach, L. A. Harker, D. D. Funk, G. Marsaglia, R. S. Hillman, S. Slichter, J. W. Adamson, A. Ganzoni, and E. R. Giblett. 1970. Ferrokinetics in man. Medicine (Baltimore). 49: 17-53.

11. International Committee for Standardization in $\mathbf{H e}$ matology. 1971. Br. J. Haematol. 20: 451-456.

12. Cook, J. D. 1970. An evaluation of absorption methods for measurement of plasma iron-binding capacity. $J$. Lab. Clin. Med. 76: 497-506.

13. Wenn, R. V., and J. Williams. 1968. The isoelectric fractionation of hens' egg ovotransferrin. Biochem. J. 108: 69-74.

14. Cavill, I., and C. Ricketts. 1980. The kinetics of iron metabolism. In Iron in Biochemistry and Medicine. A. Jacobs and M. Worwood, editors. Academic Press, Inc., New York. 574-602.

15. Huebers, H., W. Bauer, E. Huebers, E. Csiba, and C. A. Finch. 1981. The behavior of transferrin iron in the rat. Blood. 57: 218-228.

16. Huebers, H., E. Huebers, and E. Csiba. 1977. Intestinal absorption of transferrin-bound iron in normal and irondeficient rats. Blood. 50: 80.

17. Huebers, H., E. Huebers, E. Csiba, and C. A. Finch. 1978. Iron uptake from rat plasma transferrin by rat reticulocytes. J. Clin. Invest. 62: 944-951.

18. Hillman, R. S., and P. A. Henderson. 1969. Control of marrow production by the level of iron supply. J. Clin. Invest. 43: 454-460. 